Eloy Tejero

University of Navarra, Spain

\title{
El recto entendimiento del consentimiento matrimonial según Juan Pablo II
}

\section{Proper Understanding of Marital Consent according to John Paul II}

\section{Abstract}

Pope John Paul II in his teaching on marriage had not limited the issue only to the principle that matrimonial consent makes marriage, but he put a real challenge in front of the canonists stating that the proper understanding of the consent may not be reduced to a certain historical patterns, but must be developed on the basis of anthropological and legal sciences. The article discusses four issues. Firstly, the author engages in the issue of impoverishment of ius in corpus as an essential element of the contract of marriage. Then, she sketches the view of the Second Vatican Council on matrimonial consent as a mutual gift of one person to another. Subsequently, the author deals with the influence of personalism on the legal dimension of marriage. Finally, she presents the personalistic criteria in the Magisterium of John Paul II and its immediate legal dimension.

\section{Keywords}

John Paul II, marriage, personalism, matrimonial consent.

\section{Introducción}

No se limitó Juan Pablo II a recordar -como en su día hizo Pablo VI¹- la importancia del principio: el consentimiento hace el matrimonio, sino que planteó un verdadero reto a los canonistas, al asegurar que "el recto entendimiento del consentimiento matrimonial (...) no puede reducirse exclusivamente a esquemas adquiridos, válidos indudablemente aún hoy, pero que pueden perfeccionarse con el progreso en la profundización de las ciencias antropológicas y jurídicas. Aun

${ }^{1}$ Alocución 9. II. 76, n. 9. 
en su autonomía y especificidad epistemológica y doctrinal, el Derecho canónico, sobre todo hoy, debe servirse de la aportación de otras disciplinas morales, históricas y religiosas"2.

Hizo, además, Juan Pablo II aportaciones muy relevantes en el tratamiento de esta grave cuestión. Entre ellas, ésta nos parece especialmente significativa: "El Concilio ha subrayado el aspecto de la donación y ahora conviene detenerse aquí un momento para captar mejor en profundidad el significado del acto de entregarse en oblación total con el consentimiento, el cual, si se sitúa en el tiempo, asume un valor de eternidad. Un don, si quiere ser total, debe ser sin retorno y sin reservas. Por ello en el acto con el cual se expresa la donación debemos aceptar el valor simbólico de los compromisos asumidos. Quien se entrega, lo hace con el conocimiento de obligarse a vivir su don para el otro; si el otro concede un derecho es porque tiene la voluntad de obligarse; y se entrega con la intención de obligarse a realizar las exigencias del don total hecho libremente por él. Si bajo el perfil jurídico estas obligaciones se definen más fácilmente, si se expresan más como un derecho que se cede que como una obligación que se asume, es, sin embargo, verdad que el don no está más que simbolizado por los compromisos de un contrato, el cual expresa en el plano humano los compromisos inherentes a todo consentimiento nupcial verdadero y sincero. Así se llega a comprender la doctrina conciliar, así, a permitir que se recupere la doctrina tradicional para colocarla en una perspectiva más profunda y a la vez más cristiana"’3.

En orden a una percepción más abierta de los conceptos que, en la mente de Juan Pablo II, son más valiosos, para el recto entendimiento del consentimiento, bien diferenciados de otros menos acertados, apoyándonos en los estudios que antes hemos realizado ${ }^{4}$, trataremos de dar razón, en forma muy sintética, de las corrientes de pensamiento más directamente incidentes en la comprensión del consentimiento matrimonial.

\footnotetext{
${ }^{2}$ Juan Pablo II, Alocución 17. I. 1998, n. 6.

${ }^{3}$ Juan Pablo II, Alocución 28. I. 1982, n. 6.

${ }^{4}$ Sobre las aportaciones antropológicas y jurídicas, E. Tejero, ¿Imposibilidad de cumplir o incapacidad de asumir las obligaciones esenciales del matrimonio? Historia, jurisprudencia, doctrina, normativa, magisterio, interdisciplinariedad y psicopatología incidentes en la cuestión, Pamplona 2007. Respecto de los perfiles históricos y religiosos, E, Saldón, El matrimonio misterio y signo. Del siglo I a San Agustín, Pamplona 1971; T. Rincón, El matrimonio misterio y signo. Siglos IX al XII, Pamplona 1971; E. Tejero, El matrimonio misterio y signo. Siglos XIV al XVI, Pamplona 1971; J. F. Muñoz García, El matrimonio misterio y signo. Siglos XVII y XVIII, Pamplona 1982.
} 


\section{El empobrecimiento consiguiente a la consideración del ius in corpus como objeto esencial del contrato matrimonial}

El planteamiento de base contractualista, que hace el CIC17 en su consideración del matrimonio, es clave para entender por qué la doctrina y la jurisprudencia posteriores identificaron la esencia del matrimonio y el ius in corpus, y por qué, apurando extremadamente ese planteamiento, ciertos sectores de la jurisprudencia y de la doctrina insistirían en que las deficiencias en la posibilidad de uso de este derecho incapacitarían para el matrimonio. Ya en la frase inicial del c. $1012 \S$ $2 \mathrm{CIC} 17$, se acoge este criterio fundante de todo el título relativo al matrimonio: "Cristo el Señor elevó a la dignidad sacramental al mismo contrato matrimonial que tiene lugar entre bautizados". El contrato es la categoría fundamental sobre la que se asienta la contemplación del matrimonio, hasta presentar al sacramento como algo en cuya base se encuentra el contrato mismo. Es ésa la visión de la naturaleza del matrimonio que, apartándose de la tradición doctrinal anterior, presentó, a finales del siglo XVI, Gabriel Vázquez: "El matrimonio, desde su primera institución, es un contrato civil" $\mathrm{y}$ "la sustancia de este sacramento no es otra cosa que la sustancia del contrato"6.

Mientras los decretalistas clásicos destacaron la insuficiencia del concepto contrato en la visión canónica del matrimonio, "pues, de ser visto como realidad no sacramental, podría disolverse como contrato", Basilio Ponce de León, siguiendo a Gabriel Vázquez, expresó su persuasión de que el matrimonio "en cuanto contrato natural, sólo fue instituido por el derecho de la naturaleza, no por voluntad divina o humana", y concluyó que esa dimensión contractual de ámbito natural "es la misma razón de ser y sustancia del matrimonio en sí mismo considerado"s.

En conexión de fondo con este planteamiento, el c. 1081 (CIC 17) presentó el consentimiento, en su vertiente subjetiva de acto voluntario de entrega, $y$, en la objetiva, referida al "ius perpetuum et exclusivum en orden a los actos de

${ }^{5}$ G. Vázquez, Commentariorum ac disputationum in tertiam partem Sti. Thomae tomus IV, Compluti 1615, tract. De matrimonio, disp. III, cap 5, n. 57.

${ }^{6}$ Ibidem, dist. III, cap. 6, n. 73. Una presentación de la doctrina de Vázquez sobre la sacramentalidad del matrimonio puede verse en E. Tejero, El matrimonio misterio..., pp. 482-500.

${ }^{7}$ Nicolás de Tudeschis (El Panormitano), Commentaria super Decretalium, lib. III, rub. De conversione conjugatorum, Ex publico, n. 13, Lugduni 1531, fol. 167 v $^{\circ}$. Cfr. E. Tejero, El matrimonio misterio.., pp. 42-43. En esta misma obra, p. 563, pueden verse más referencias sobre este mismo tema.

${ }^{8}$ B. Ponce de León, De sacramento matrimonii tractatus, lib. I, cap. 3, n. 9, Lugduni 1640, p. 6. Cfr. F. Muñoz García, El matrimonio misterio y signo. Siglos XVII y XVIII, Pamplona 1982, p. 127. En esta misma obra, p. 549, pueden verse más referencias sobre ese mismo tema. 
por sí aptos para la generación de la prole". A partir de ese canon, la doctrina inmediatamente posterior no tuvo duda alguna de que en él se había tipificado el objeto formal del contrato matrimonial'. Parecía haberse logrado así una delimitación del objeto esencial del contrato, cuyo carácter elemental podría asegurar su aceptación por parte de todo tipo de contrayentes, como también la posible delineación de una cierta voluntad negocial de parte de los contratantes, ya que, así diseñado el objeto del contrato, estaríamos ante un ámbito que, en orden a la emisión de una voluntad dirigida a ese objeto, de forma específica y directa -como ocurre en las cláusulas de los contratos-, podría considerarse de aceptación más o menos generalizada por parte de los contrayentes.

Este reduccionismo de la esencia del matrimonio in fieri y del in facto esse al ius in corpus ${ }^{10}$, dio paso a notables dificultades para la determinación de los valores esenciales del matrimonio que disciplina el ordenamiento canónico. En efecto, no favorece la correcta captación de los niveles esenciales del matrimonio cristiano la fluidez característica del régimen jurídico de los contratos, abiertos, en principio, a la libre determinación de sus contenidos por parte de los contratantes. Por otra parte, estando expuestos siempre los contratos al principio "res per quas causas nascitur, per easdem disolvitur", dimana de la categoría contrato un óbice fundamental a la acogida de valores tan específicos del sistema matrimonial canónico como la indisolubilidad del vínculo ${ }^{11}$. Son estos inconvenientes de

${ }^{9}$ P. Gasparri, Tractatus canonicus de matrimonio, Typis Polyglottis Vaticanis 1932, n. 7; I. Pasquazi, De iure in corpus in ordine ad actos per se aptos ad prolem generationem, en “Apollinaris" 1953, pp. 393-395; E. Regatillo, Ius sacramentarium, Santander 1949, pp. 55-556; J. Mans, Derecho matrimonial canónico, I, Barcelona 1959, p. 8; C. A. Coronata, Institutiones Iuris canonici, III. De sacramentis, Romae 1957, n. 4; M. Capello, De matrimonio, Romae 1961, n. 6; L. Miguélez, Comentarios al Código de Derecho canónico, II, Madrid 1963, n. 284; Ha sintetizado este planteamiento M. E. Olmos Ortega, La definición del matrimonio y su objeto esencial: 19171960, en AA. VV., El «consortium totius vitae.en "Curso de Derecho Matrimonial y Procesal para profesionales del foro", VII, 1986, pp. 11-36.

${ }^{10}$ Una síntesis acertada de este planteamiento puede verse en E. Molano, Contribución al estudio de la esencia del matrimonio, Pamplona 1977, pp. 129-151.

${ }^{11}$ Th. Vlaming - L. Bender, Praelectiones Iuris matriminii, Bussum 1950, p. 3; S. Lener, L'oggetto del consenso e l'amore nel matrimonio en "Annali di doctrina e giurisprudenza canonica”, I. L'amore coniugale, Città del Vaticano 1971, pp. 146-147. De ahí el acierto con que ha hecho notar S. Lener, que debe abandonarse la categoría contractual al dar razón del orden propio de la relación matrimonial, por las siguientes razones: a) "La primera y más común razón está en que, en las situaciones constituidas por el contrato, la ley o regulación objetiva de la relación viene puesta y determinada esencialmente por la concorde voluntad de las partes". b) la segunda razón va dirigida específicamente a la consideración del ius in corpus como objeto formal del contrato: "no se niega, con esto, el poder-deber de los cónyuges de poner entre ellos los actos idóneos para la generación de la prole. Se niega, en cambio, que el objeto del contrato matrimonial sea ese ius o el contenido del mismo (actos o prestaciones); y se niega además que la fuente o causa 
fondo los que obligan a buscar una rectificación básica a la dogmática de los contratos al ser aplicada al matrimonio: es necesario suponer la existencia de un objeto esencial del contrato, que, viniendo determinado por el Derecho natural, necesariamente deberán atenerse a él las partes contratantes: deben convenir, precisamente, sobre ese objeto esencial previamente determinado por el mismo Derecho natural. Así pierden las partes, en el contrato que es el matrimonio, la libre autonomía para fijar las cláusulas de su acuerdo, que es la esencia del contrato en cuanto acto de privada iniciativa ${ }^{12}$.

$\mathrm{Al}$ incluir en la estructura jurídica de los contratos un objeto del matrimonio esencialmente predeterminado por el Derecho natural, se intenta unir dos elementos jurídicamente heterogéneos: ni el contrato es un concepto útil para captar los contenidos de Derecho natural que se imponen a los contrayentes como supuesto objeto esencial del consentimiento matrimonial, ni esta imposición de un objeto esencial en el contrato contribuye nada a una comprensión adecuada de la esencia de los contratos. De esa heterogeneidad procede que, al pretender extraer las consecuencias que deberían derivarse de la naturaleza contractual del matrimonio y de la imposición a los contratantes de un objeto esencial preestablecido, resulta imposible hacer una ilación lógica entre los postulados propios del punto de partida -la esencia del contrato- y la típica ordenación del matrimonio, que repudia la libertad de los contratantes para pactar los contenidos de su acuerdo. De esa heterogeneidad proviene que este discurso no puede hilvanar ni un solo razonamiento sobre la supuesta predeterminación del ius in

eficiente (directa) del dicho ius sea la traditio, que cada nubente haría al otro". c) La tercera razón se refiere al momento más sustancial de la concepción contractualista", en la cual el consentimiento matrimonial se concreta precisamente en un contrato sinalagmático, ya que su contenido (objeto o causa específicamente) está en la mutua deditio, o traditio, directamente intercambio del ius in corpus. d) Finalmente Lener demuestra la inadecuación de la categoría contractual para explicar de modo satisfactorio las dos propiedades esenciales del matrimonio -la unidad y la indisolubilidad-, que constituyen una excepción a la lógica contractualísta. S. Lener, L'oggetto del consenso $e$ l'amore nel matrimonio, en AA. VV., Anannali di dottrina e giurisprudenza canonica, I, L'amore coniugale, Citta del Vaticano, 1071, pp. 125-127. Cfr. J. Carreras, L'antropologia e la norma..., p. $132-133$.

${ }^{12}$ Como ha hecho notar recientemente T. Blanco, la forma en que se recoge la noción abstracta de contrato "varía según los ordenamientos. Así, mientras que unos, como el civil italiano, o el francés, la plasman explícitamente en un artículo (1321 y 1101 respectivamente), otros como el código civil español o el portugués, la dan por supuesta. (...) Esta diversidad se refleja también en cuanto a los contenidos que cada legislador considera esenciales en la noción de contrato. Así, en unos ordenamientos el concepto contrato aparece como una relación jurídica amplia, que puede tener por objeto los más diversos contenidos, ya sean éstos personales, familiares, patrimoniales, etc. Otros, en cambio, limitan el concepto a las relaciones jurídicas de contenido estrictamente patrimonial”. La noción canónica de contrato. Estudio de su vigencia en el CIC 1983, Pamplona 1997, pp. 40-41. 
corpus, como objeto esencial, en coherencia con la esencia del contrato, que es la libre determinación del acuerdo contractual ${ }^{13}$. Esta visión del matrimonio sólo puede ofrecernos unas fórmulas barrocamente recargadas de adjetivos y adverbios, derivados de los sustantivos sustancia, esencia o naturaleza, -ex natura rerum ius in corpus est obiectum formale substantialiter contractus-, porque ese planteamiento, específicamente contractual, no tiene posibilidades de penetrar en los valores esenciales del matrimonio de la creación ni del específicamente cristiano.

Además, estando abiertos los contratos a los más variados intereses materiales y crematísticos de las partes, confieren una cierta racionalidad a la entrega de los cuerpos "como objeto de concupiscencia y, por tanto, como 'terreno de apropiación' del otro ser humano. La concupiscencia, de por sí, no es capaz de promover la unión como comunión de personas. Ella sola no une, sino que se adueña. La relación de don se transforma en la relación de apropiación"14. Como consecuencia, "si el hombre se relaciona con la mujer hasta el punto de considerarla sólo como un objeto del que apropiarse y no como don, al mismo tiempo se condena a sí mismo a hacerse también él, para ella, solamente objeto de apropiación y no don (...). Por otra parte, en la apropiación unilateral (que indirectamente es bilateral) desaparece la estructura de la comunión entre las personas; ambos seres humanos se hacen casi incapaces de alcanzar la medida interior del corazón, orientada hacia la libertad del don y al significado nupcial del cuerpo, que le es intrínseco" 15 .

Y, precisando más la injusticia de fondo que implica esa relación de apropiación bilateral inherente a la visión objetivada de las personas o de las prestaciones mutuas, como si estuviéramos ante actos de dominio, hace notar Juan Pablo II que, si bien la dimensión de la unión personal del hombre y la mujer a través del amor se expresa en las palabras como "mío...mía", sin embargo, son pronombres que en su significado material denotan una relación de posesión. De ahí que podemos hablar de la pertenencia recíproca de las personas solamente si tomamos esos términos en la forma de la analogía personal en que los utiliza el lenguaje del amor humano. "Pero la analogía -como se sabe- indica a la vez la semejanza y también la carencia de identidad. (...) En efecto, en su significado originario y específico, la pertenencia supone relación de sujeto con objeto: relación de

\footnotetext{
${ }^{13}$ S. Lener, L'ogetto del consenso..., pp. 146-147.

${ }^{14}$ Juan Pablo II, Alocución, 23. VII. 1980, n. 6.

${ }^{15}$ Idem, Alocución, 30. VII. 1980, n. 1.
} 
posesión y de propiedad. Es una relación no solamente objetiva, sino sobre todo 'material'; pertenencia de algo (por tanto de un objeto) a alguien"'

Como se ve, esta visión de la pertenencia objetiva y la mutua posesión, que el Magisterio papal considera desajustada, se encuentra en la entraña de la visión jurídica del matrimonio que tienen los contractualistas, como relación jurídica sujeto-objeto. Respecto de la problemática que aquí venimos estudiando, es éste un punto clave, pues, siendo para los contractualistas el objeto del contrato la única vía de acceso a la esencia del matrimonio, los desajustes que Juan Pablo II viene detectando en este planteamiento ponen de relieve el desenfoque esencial que ese planteamiento implica.

Por otra parte, ese planteamiento del objeto esencial del contrato ha sido la base desde la cual se ha construido la supuesta relevancia de la imposibilidad incapacidad para cumpliry disfrutar, de hecho, de los llamados derechos esenciales del matrimonio. Pero esa exigencia de disfrute actual y efectivo también ha sido abiertamente desautorizada por Juan Pablo II: "La triple concupiscencia y, en especial, la concupiscencia de la carne, quita a la recíproca pertenencia del hombre y de la mujer la dimensión que es propia de la analogía personal, en la que los términos 'mío... mía' conservan su significado esencial. Tal significado esencial está fuera de la 'ley de la propiedad', fuera del significado del 'objeto de posesión'; la concupiscencia en cambio, está orientada hacia ese último significado. Del poseer, el ulterior paso va al 'gozar': el objeto que poseo adquiere para mí un cierto significado en cuanto que dispongo y me sirvo de él, lo uso. Es evidente que la analogía personal de la pertenencia se opone decididamente a ese significado. Y esta oposición es un signo de que lo que en la relación recíproca del hombre y de la mujer 'viene del Padre' conserva su persistencia y continuidad en contraste con lo que viene 'del mundo'. Sin embargo, la concupiscencia de por sí empuja al hombre hacia la posesión del otro como objeto, lo empuja hacia el 'goce', que lleva consigo la negación del significado nupcial del cuerpo. En su esencia, el don desinteresado queda excluido del 'goce' egoísta"17.

Estamos ante la crítica más penetrante al corrimiento esencial del orden jurídico matrimonial que implica la consideración del cumplimiento efectivo, de la realización, ejecución y disfrute actual de los derechos como datos supuestamente esenciales del orden divino del matrimonio. Sólo la concupiscencia inherente al tráfico contractual de la vida ordinaria puede contribuir a dar una cierta lógica persuasiva al discurso que se alimenta de esos conceptos. De nada servirá el hecho de que, en tiempo anterior, haya habido momentos, más o menos dilatados,

\footnotetext{
${ }^{16}$ Ibidem, n. 3.

${ }^{17}$ Ibidem, n. 4.
} 
en que el cumplimiento y disfrute de los derechos haya podido ser satisfactorio, porque, de no ser posible el disfrute actual, se tornarán contra la persona que ya no puede garantizar prestaciones anteriormente dadas. Se exigirá una posibilidad capacidad perpetua de cumplir.

Se ha de notar, además, que la reducción de la esencia del matrimonio in facto esse a uno o varios derechos subjetivos, que hace el contractualismo, no es posible encontrarla en ninguna de las tipificaciones del matrimonio contenidas en la Escritura, en el Derecho romano ni en las fuentes canónicas, con anterioridad al CIC17. El Derecho anterior a la primera codificación presentó siempre al matrimonio, desde la perspectiva de su orden institucional, como "unión de dos en una carne"18; como "unión del hombre y la mujer, consorcio de toda la vida, que contiene una comunión de derecho humano y divino"19; como unión del hombre y de la mujer que contiene una costumbre de vida individua, indivisible ${ }^{20}$. Es de notar que esta visión de la esencia del matrimonio es la que encontramos también en la gran tradición cristiana, pues "el matrimonio en su sentido más propio hace referencia al vínculo y es ésta la enseñanza de Santo Tomás ( 3 pars, q. 44, a. 1) y convencen de lo mismo Platón y Aristóteles y se colige del Génesis 2, 18-24, donde, para explicar la esencia del matrimonio se dice del varón: 'Y se unirá a su mujer y serán dos en una carne', y esta referencia la aduce San Pablo para explicar la unión de Cristo con la Iglesia"21.

\section{El consentimiento visto por el Concilio Vaticano II como donación personal mutua de naturaleza sacramental}

En contraste con los planteamientos expuestos en el apartado anterior, es muy significativo que el magisterio del Vaticano II sobre el matrimonio nunca menciona la categoría contrato y no quiso acoger tampoco el concepto ius in corpus, que en los planteamientos antes expuestos se venía presentando como

\footnotetext{
${ }^{18} \mathrm{X}, \mathrm{I}, \mathrm{XXI}, 5$.

${ }^{19}$ Modestino, D. 23, 3, 1.
}

${ }^{20}$ Ulpiano, Inst. I, 8, 1. Bastante afín a esta consideración del matrimonio es la que, con Pedro Lombardo, (Sententiarum lib. IV, dist. XXVII), ofrecerán muchos textos teológicos y canónicos de la Edad Media: "Viri mulierisque coniunctio individuam consuetudinem retinens". Cfr. Pío Fedele, La definizione del matrimonio in diritto canonico, en "Ephemerides Iuris Canonici" 51 (1945); O. Robleda, Intorno alla nozione di matrimonio nel diritto romano e nel diritto canonico, en "Apollinaris" 50 (1977) 172-193.

${ }^{21}$ P. Cornejo, In tertiam partem Sancti Thomae, trac. De matrimonio, disp. I, dub. I, in Monte Carmelo Pinciano 1629, p. 842. Cf. E. Tejero, El matrimonio misterio..., p. 508. 
esencia del matrimonio in fieri y del matrimonio in facto esse. Tales cambios provocaron reacciones de algunos Padres, que defendieron la inclusión de esas categorías: el relator del schema II, llamado también textus receptus, tuvo que justificar en estos términos la ausencia de la categoría contrato: "No se hace mención del 'contrato matrimonial', sino que con palabras más claras se habla del 'irrevocable consentimiento personal', de acuerdo con los votos de los Padres (...). Se añade el término bíblico alianza en atención a los Orientales, para quienes 'contrato' ofrece ciertas dificultades"22.

Por consiguiente, la opción del Concilio obedece a sólidas razones: "Los motivos de fondo de esta negativa a la contractualidad del matrimonio se centran en el deseo de delimitar con claridad la autonomía de los nubentes pretendiendo, al mismo tiempo, evitar una concepción errada de la voluntad de las partes como si fuera soberana, no sólo en el momento de constituir y dar existencia a la relación jurídica, sino también en la determinación de tal relación" ${ }^{23}$. Respecto del ius in corpus, la conveniencia de su mención se propuso por 34 Padres que defendieron la mención de los "específicos derechos y deberes que los cónyuges legítimamente se entregan y aceptan mutuamente" ${ }^{24}$. Pero tampoco esa propuesta, reflejo de la mentalidad típica del esquema sinalagmático aplicado al matrimonio, mereció ser acogida.

Prefirieron los padres conciliares presentar el significado del consentimiento matrimonial desde una óptica diferente, como entrega mutua de los esposos de naturaleza sacramental: "Pues de la misma manera que Dios en otro tiempo salió al encuentro de su pueblo con una alianza de amor y fidelidad, ahora el Salvador de los hombres y Esposo de la Iglesia, mediante el sacramento del matrimonio, sale al encuentro de los esposos cristianos. Permanece además con ellos para que, como El amó a la Iglesia y se entregó por ella, así también los cónyuges, con su mutua entrega, se amen con perpetua fidelidad. El auténtico amor conyugal es asumido en el amor divino y se rige y se enriquece por la fuerza redentora de Cristo y la acción salvífica de la Iglesia, para conducir eficazmente a los esposos

${ }^{22}$ F. Gil Hellín, Constitutionis pastoralis «Gaudium et spes» synopsis historica. De dignitate matrimonii et familiae. II pars, caput I, Pamplona 1982, p. 48.

A la vista de estos datos, ha concluido Mons. Gutiérrez Martín: "Por la historia de las deliberaciones y trabajos conciliares se sabe que el vocablo contrato había de evitarse con el fin de poner más de relieve los elementos objetivos del matrimonio independientes de la voluntad de las partes y para disipar de esta manera las reservas que los Orientales abrigan contra al contrato aplicado al matrimonio". Voluntad y declaración en el matrimonio, Salamanca 1990, pp. 130-131.

${ }^{23}$ G. Mantuano, La definizione giuridica del matrimonio nel magistero conciliare, en Ciesa dopo il Concilio, Milano 1972, p. 894.

${ }^{24}$ F. Gil Hellín, Constitutionis pastoralis..., p. 50. 
a Dios y ayudarlos y fortalecerlos en la sublime tarea de padre y madre. Por eso los cónyuges cristianos son fortalecidos y como consagrados para los deberes y la dignidad de su estado por este sacramento especial, en virtud del cual, cumpliendo su deber conyugal y familiar, imbuidos del espíritu de Cristo, con el que toda su vida está impregnada por la fe, la esperanza y la caridad, se acercan cada vez más a su propia perfección y a la santificación mutua y, por tanto, a la glorificación de Dios en común" 25 .

Aunque esta visión conciliar del consentimiento matrimonial pudiera parecer nueva, respecto de los planteamientos anteriores, en realidad, es una recuperación "de la doctrina tradicional para colocarla en una perspectiva más profunda y a la vez más cristiana" ${ }^{26}$. En efecto, a diferencia de otras visiones del matrimonio, que desarrollan su discurso como si la Revelación cristiana no ofreciera dato alguno significativo en la ordenación divina del matrimonio, la que lo contempla como sacramento lo hace en directa asimilación de los datos de la Escritura sobre el matrimonio originario y sobre su restauración hecha por Cristo. La hondura de estas enseñanzas divinas no sólo da origen a una teología sobre el matrimonio, sino que tiene también una incidencia básica en el régimen jurídico que el sistema matrimonial canónico de todos los tiempos ha de plasmar con fidelidad, porque, de otro modo, no podría la Esposa de Cristo mantener su fidelidad a la doctrina que, en depósito, le ha sido confiada. Se comprende por eso que tanto la patrística, como el derecho canónico clásico, la teología medieval y la que hubo de responder a los planteamientos de Lutero sobre el matrimonio, mantuvieran que la significación sacramental del matrimonio es el valor fundante del orden divino del matrimonio y la pieza básica del sistema matrimonial canónico que da coherencia a los diferentes núcleos que lo componen ${ }^{27}$.

A partir de esta conformación interior del matrimonio por el orden de la relación que, según Ef. 5, 22-33, media entre Cristo y su Iglesia, el consentimiento que hace el matrimonio también adquiere un valor de signo sacramental que no puede ser silenciado: "Cuando el esposo manifiesta con palabras su mutuo consentimiento expresa como una fórmula sacramental (...) y actúa como tipo de Cristo, a Quien representa, comprometiéndose a ser para su esposa, como Cristo, ardiente celador, defensor acérrimo de su integridad, salvador de su vida"28. "El hecho de que la mujer se una a su varón como la Iglesia a Cristo; y el varón a su mujer como

${ }^{25}$ GS, n. 48.

${ }^{26}$ Juan Pablo II, Alocución 28. I. 1982, n. 6.

${ }^{27} \mathrm{Cf}$. las monografías sobre El matrimonio misterio y signo citadas en nota 4.

${ }^{28}$ Gillermo Van der Linden, Panoplia Evangelica, lib. IV, cap. XCIV, Parisis 1564, fol. 435v. Cfr. E. Tejero, El matrimonio misterio..., p. 399. 
Cristo a su Iglesia da origen a que su matrimonio sea una unión que hace sagradas y santifica a las almas (...), por lo cual el matrimonio de los cristianos es signo de institución divina como los demás sacramentos"29. "El matrimonio es una sancta sanctificativa et perfecta societas del varón y de la mujer" ${ }^{30}$. Por eso, "aunque en el sacramento del matrimonio no encontremos sino el consentimiento de los contrayentes, sin embargo, ese mismo acto de los contrayentes es como el opus operatum" $"$.

En relación con la esencia del matrimonio in fieri, es necesario tener en cuenta que, de acuerdo con su naturaleza sacramental, los factores del matrimonio tienen una operatividad y eficacia típicamente sacramentales, que sólo pueden ser adecuadamente valorados en coherencia con los postulados de la más autorizada doctrina sacramentaria: "Como el agua del bautismo juntamente con la forma verbal no opera inmediatamente la gracia, sino el carácter; así los actos exteriores y las palabras que expresan el consentimiento directamente operan el nexo, que es el sacramento del matrimonio; y este nexo por la fuerza de la institución divina opera dispositivamente la gracia" 32 . "Como en los demás sacramentos, en el matrimonio, una cosa es la res tantum, otra es el signum tantum y otra la res et signum. Esto es general en todos los sacramentos" ${ }^{33}$. "Los actos exteriores, por los cuales las personas que contraen matrimonio se obligan mutuamente, son el sacramentum tantum, pero la gracia dada por Dios a las personas que contraen legítimamente es la res sacramenti tantum, y la misma obligación mutua y perpetua de las personas que contraen es el sacramentum et res. Pues respecto de los actos exteriores, que son el sacramentum tantum, esta obligación es res et sacramentum, pero respecto de la gracia, que causa, es el sacramentum ${ }^{34}$.

${ }^{29}$ San Roberto Belarmino, De controversiis christianae fidei, De matimonii sacramento, cap. V, Coloniae Agripinae 1615, t. III, p. 506. Cfr. E. Tejero, El matrimonio misterio..., p. 452.

${ }^{30}$ Guillermo de Auvernia, De sacramento matrimonii liber unus, Venetiis 1591, p. 485. Cfr. T. Rincón, El matrimonio misterio...., p. 273.

${ }^{31}$ Pedro de Ledesma, De magno matrimonii sacramento, q. XLII, art. II, Salmanticae 1592, p. 33. Cfr. E. Tejero, El matrimonio misterio..., p. 430.

${ }^{32}$ Supl. q. 42, a. 3 ad 2.

${ }^{33}$ San Buenaventura, Commentaria in librum IV Sententiarum, dist. XXVI, a. 2, q. I. Cfr. T. Rincón, El matrimonio misterio..., p. 307.

${ }^{34}$ Tomás de Argentina, Commentaria in quattuor libros Sententiarum, lib. IV, q. I, art. I, Genovae 1585, fol. $151 v^{\circ}$. Cfr. E. Tejero, El matrimonio misterio..., p. 77. Este texto reitera la doctrina expuesta por Santo Tomás, Supl., q. 42, a. 1 ad 5. y es expresada por muchos autores posteriores: Francisco Silvestre de Ferrara, Commentarii Summae contra gentiles, lib IV, cap. 78, concl. II. Cfr. E. Tejero, El matrimonio misterio..., p. 150; Tomás Vio Cayetano, Opuscula, t. II.

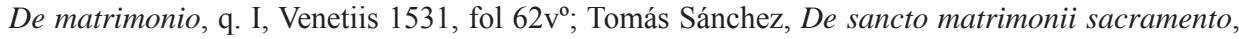
lib. II, disp. X, n. 2, Lugduni 1739, p. 123. Cfr. E, Tejero, El matrimonio misterio..., p. 470; Juan 


\section{The Person and the Challenges \\ 174 Volume 2 (2012) Number 1}

Como en los otros sacramentos, "en el matrimonio hay algo permanente, y esto es el vínculo, por el cual están ligados el varón y la mujer, por más que externamente estén separados; y hay algo transeúnte, como la unión primeramente hecha por la palabra exterior y ambas son unión" ${ }^{35}$. Pero el hecho de que el consentimiento sea la causa eficiente de la coniunctio sacramentalis no puede llevarnos a concluir que resida en el consentimiento la esencia del matrimonio, pues "en el matrimonio hay que considerar tres cosas. Primero, su esencia, que es unión. Y según esto es llamado conyugio. Segundo su causa, que es la desponsatio (...). En tercer lugar, su efecto que es la prole" ${ }^{36}$. Aunque pueda decirse que el consentimiento es de la sustancia del matrimonio, por su necesidad para que exista la unión matrimonial, sin embargo, "el matrimonio no es el mismo consentimiento, sino cierta unión de los ordenados a un fin, como se ha dicho, la cual es hecha por el consentimiento" ${ }^{37}$.

Más matizada y desarrollada es la precisión que hace Gonet: "El matrimonio formal y esencialmente consiste en el vínculo: pues no puede consistir formal y esencialmente en el consentimiento mutuo del varón y la mujer, por ser la causa eficiente del matrimonio (...); pues la causa formal es intrínseca, pero la eficiente

de Lugo, De sacramentis in genere, disp. II, sect. 8, n. 145, Lugduni 1644, p. 41. Cfr. F. Muñoz García, El matrimonio misterio..., p. 55; Juan Bautista Gonet, Clypeus Theologiae thomistae, t. V, tract. 8, disp. 2, a. 1, n. 19, Antuerpiae, 1774, p. 363; Juan Clericato, De sacramento matrimonii, en Decissiones sacramentales, t. II, decis. 2, n. 12, Venetiis 1757, p. 6; A. Reiffenstuel, Theologia moralis, t. II, trac. 13, dist. 1, q. 2, nn. 16-17, Barcinone 1736, p. 3; Salmanticenses, Cursus Theologiae moralis, t. II, trac. IX, De sacramento matrimonii, c. 3, n. 45, p. 71; Luis Vicente Gotti, Theologia scholastico-dogmatica iusta mentem Divi Thomae Aquinatis, tom. III, tract. 13, q. I, dub I, n. 13, Venetiis 1793, p. 433; Carlos Billuart, Summa Sancti Thomae sive cursus theologiae, t. X, De matrimonio, dist. 4, art. 1, Parisiis 1857, p. 142; P. M. Gazzaniga, Praelectiones theologiae, t. VIII, dist. 9, c. 3, n. 48, Venetiis 1803, p. 256; Francisco Schmalzgrueber, Ius ecclesiasticum universum, in V libros decretalium Gregorii IX, t. VIII, pars I, n. 311, Romae 1844, p. 142; Claudio Frassen, Scotus academicus, seu universa Doctoris subtilis theoligica dogmata, t. XII, De sacramento matrimonii, art. 1, q. I, concl. 2, Roma 1902, p. 140; Francisco Noël, F. Suárez theologiae summa, seu compendium, tom. I, trac. De matrimonio, appendix, 2, pars, 3, c. 1, Matriti 1732, p. 47; Jacinto Drouven, De re sacramentaria, t. II, lib. 10, q. 3, Venetiis 1756, p. 511. Más referencias sobre este punto pueden verse en T. Rincón, El matrimonio misterio..., pp. 443-444, voces: Eficacia teológicosacramental del matrimonio, Perfección del vínculo, "Res sacaramenti", Sacramentum, Vinculum. También E. Tejero, El matrimonio misterio..., pp. 563, 565-566, voces: Consentimiento, Gracia sacramental del matrimonio, Sacramentalidad del matrimonio, Sacramentum tantum, Vínculo matrimonial "res et sacramentum".

${ }^{35}$ San Buenaventura, Commentaria in IV librum Sententiarum, dist. XXVII, a. 1, q. I. Cfr. T. Rincón, El matrimonio misterio..., p. 306.

${ }^{36}$ Santo Tomás, Supl.., q. 44, a. 2. La misma doctrina se expone en el artículo siguiente: "Como se ha dicho, en el matrimonio se consideran tres cosas: es decir, su causa, su esencia y su efecto. Y según esto se encuentran tres definiciones del matrimonio". Supl., q. 44, a, 3.

${ }^{37}$ Ibidem, q. 45, a. 1, ad 2. 
está entre las extrínsecas"38. "Digo con brevedad que el matrimonio consiste formal y esencialmente en el vínculo por el cual los cónyuges están unidos (...) Y no vale decir que, aunque pase el consentimiento actual, permanece sin embargo, y moralmente persevera el consentimiento habitual, y que por ello puede consistir en él formalmente el matrimonio" 39 .

En sintonía con los referidos criterios se manifestó así Tomás Sánchez: "Ni el consentimiento interno, ni el contrato exterior son aquello en que consiste la esencia del matrimonio, porque son las causas eficientes del matrimonio, también porque pasan, mientras el matrimonio dura hasta la muerte. Ni es la esencia del matrimonio la mutua entrega de los cuerpos: porque pasa ésta mientras el matrimonio permanece: ni la mutua obligación y sujeción para dar el débito. Pues ésta cesa por adulterio de alguno de ellos, o por ingreso en religión de mutuo consentimiento mientras permanece el vínculo del matrimonio consumado. Consiste, por consiguiente la esencia del matrimonio, o el matrimonio mismo en el vínculo, por el que están formalmente unidos los cónyuges que nace de la mutua entrega" ${ }^{40}$.

Contemplada la razón de ser del consentimiento desde la naturaleza sacramental del matrimonio, el discurso sobre su necesidad, sus contenidos y su eficacia fluye pautado por unos criterios muy diferentes del razonamiento que, según vimos antes, arranca de la naturaleza contractual del matrimonio. En la doctrina sacramentaria, las actuaciones de quienes hacen el sacramento no pueden ser adecuadamente comprendidas desde el principio de la libre disposición de las partes, que es el criterio básico de toda actuación de ámbito contractual. Por el contrario, las actuaciones de ámbito sacramental están presididas siempre por un principio de apertura y adhesión de los fieles a un ordenamiento divinamente instituido y realizado por la eficacia específica del sacramento, sin que el entendimiento ni la voluntad del sujeto tengan que filtrar ni determinar los contenidos ni los efectos propios de cada sacramento, ni ser previamente capaces de realizar las obligaciones dimanantes del sacramento.

De ahí proviene que sean de contenido muy diferente los actos contractuales y los sacramentales. Presididos los primeros por el principio de libre disposición, sólo es posible detectar el nacimiento de obligaciones contractuales mediante el análisis de los contenidos propios del objeto, en que libremente han convenido y

${ }^{38}$ J. B. Gonet, Manuale thomistarum seu totius theologiae brevis cursus, pars 3, trac. 7, c. 2, Antuerpiae 1742, p. 183. Cfr. J. F. Muñoz, El matrimonio misterio..., p. 66.

${ }^{39}$ J. B. Gonet, Clypeus thelogiae thomistae, t. V, trat. 8, disp. 1, a. 1, nn. 2-4, Antuerpiae 1744, p. 354. Cfr. J. F. Muñoz, El matrimonio misterio..., p. 66.

${ }^{40}$ T. Sánchez, De sancto matrimonii sacramento, lib. II, disp. 5, nn. 5-7, Lugduni 1739, pp. 118 119. 
pactado las partes. De ahí proviene que toda referencia a los contenidos esenciales del matrimonio, hecha desde la óptica contractualista, deba polarizarse sólo sobre el objeto convenido; pues, fuera del objeto libremente acordado, no es posible hallar ninguna otra pieza determinante de una conducta debida en justicia entre las partes. No ocurre así en el análisis de los actos sacramentales, porque, si bien se inician, ordinariamente, por la libre decisión del sujeto que voluntariamente accede a ellos, la sustancia de su sacramentalidad y de su operatividad no dimanan de haber sido hechos objeto directo de la libre voluntad de las partes, sino de la operatividad específica con que Cristo ha dotado a tales actos sacramentales. En el consentimiento, "nuestros actos son partes del sacramento y son sacramentos del poder divino (...), de manera que el hombre no es el agente principal, sino Dios" ${ }^{41}$. Es decir, que, mediante el mutuo consentimiento, por virtud divina, se opera la spiritalis coniunctio, pues "en todos los sacramentos hay alguna spiritalis operatio, mediante la operación material que la significa" ${ }^{\prime 2}$.

Como consecuencia de imaginar una pretendida necesidad de precisar un objeto esencial del consentimiento matrimonial, o un reducto accesible a la generalidad de los contrayentes, como el ius in corpus, constituyéndolo en núcleo sobre el cual, ineludible y esencialmente, deban convenir las voluntades de los esposos, se está suponiendo que los plurales contenidos del orden matrimonial y las diversas motivaciones, que pueden inducir a los esposos a querer unirse en matrimonio, serían insuficientes para conformar una voluntad específicamente matrimonial, si no recondujeran a las voluntades hacia el ius in corpus, como objeto única y esencialmente consistente del libre querer personal. Como si éste quedara vanificado dirigiéndose hacia otros contenidos matrimoniales, que no quedaran incluidos en tal reducto objetivo, supuestamente único, para que pueda decirse que estamos ante una voluntad matrimonial.

Antes de que tal visión del llamado objeto esencial del matrimonio fuera rectificada por el c. $1057 \S 2$ del CIC hoy vigente, ya resultaba absolutamente incoherente con la consideración del consentimiento como sacramentum tantum del matrimonio, cuya dinámica operativa no puede ser supeditada a tal reduccionismo. De ahí que Santo Tomás, en coincidencia con lo establecido en el c. 1057 § 2 del CIC83, hiciera esta nítida afirmación: "El consentimiento que hace el matrimonio, es consentimiento en el matrimonio; porque el efecto propio de la voluntad es eso mismo que es querido. Por tanto, como la cópula carnal está

${ }^{41}$ P. de Ledesma, De magno matrimonii sacramento, q. XLII, art. 1, Salmanticae 1592, p. 37. Cfr. E. Tejero, El matrimonio misterio..., p. 433.

${ }^{42}$ Santo Tomás, Supl. , q. 45, a. 1; Idem, In IV Sententiarum, dist. XXVII, q. 1, a. 2.; Henriquez, Summa theologiae moralis, lib. IX, cap. 8, n. 2, Salmanticae 1593, p. 942. 
relacionada con el matrimonio, así el consentimiento que causa el matrimonio lo está con la cópula carnal. Pero el matrimonio no es esencialmente la cópula carnal, sino cierta asociación del varón y de la mujer en orden a la cópula carnal y otras realidades que consecuentemente pertenecen al varón y a la mujer”43.

La pretensión de percibir, desde la dogmática jurídica de los contratos, el valor esencial que el consentimiento matrimonial tiene para hacer el matrimonio, además de originar los desajustes que acabamos de señalar, se muestra igualmente insuficiente a la hora de explicar la incidencia específica que el ordenamiento canónico atribuye a otros factores, como el bautismo y la unión de los cuerpos, en la ratificación y acabamiento consumado de la relación matrimonial ${ }^{44}$. En efecto, desde el prisma de los contratos, no hay posibilidad alguna de que incida la situación de bautizado en la relación jurídica matrimonial, supuestamente de naturaleza contractual. Los contractualistas, respecto de este punto, ordinariamente guardan un silencio equivalente a una ignorancia práctica de esta disposición específicamente canónica. En ocasiones, pretenden aplicar su lógica contractualista, para explicar el contenido propio de la ratificación, separada de la naturaleza sacramental de la relación matrimonial, incurriendo en apreciaciones verdaderamente llamativas.

Especialmente significativa resulta, a este propósito, la opinión de Gabriel Vázquez, el primer gran defensor de la esencia contractual del matrimonio: "La razón por la cual el matrimonio de los bautizados no puede disolverse nunca (...) es que, cuando cada uno de los cónyuges recibe el bautismo y ha profesado en él la fe católica, de tal manera se hace uno de la Iglesia, que, por razón del carácter que nunca se puede borrar, permanece siempre sujeto a ella, y puede ser castigado por la Iglesia, por causa de la herejía, y puede obligarle a que habite con el cónyuge fiel sin contumelia del Creador o, en otro caso, puede incluso condenarlo a pena de muerte, si es necesario y persevera pertinazmente en la herejía, lo que es suficiente en favor del cónyuge fiel, pues así se logrará o que el hereje habite sin contumelia del Creador, o que muera, y así, el fiel permanece libre para que pueda contraer con otro. Pero si el cónyuge que incurre en herejía huye muy lejos, de manera que no pueda ser castigado ni obligado por la Iglesia, esto ocurre per accidens y no es suficiente para decir que por esta causa se le conceda el privilegio de que sea disuelto su matrimonio (...) lo que sería absurdo"45.

A diferencia de esta visión tan peculiar de la ratificación del matrimonio, reducida a total sometimiento del bautizado al juicio severísimo de la Iglesia,

\footnotetext{
${ }^{43}$ Supl. q. 48, a. 1.

${ }^{44}$ Cfr. C. $1061, \S 1$ del CIC83 y el c. 1015 , \& 1 del CIC17.

${ }^{45}$ Gabriel Vázquez, Commentariorum , disp. II, cap. VII, n. 78, p. 494.
} 


\section{The Person and the Challenges \\ 178

completamente alejada del ámbito sacramental del matrimonio, encontramos en el Derecho canónico clásico esta otra justificación de la entidad específica del matrimonium ratum: "El bautismo es el primer sacramento de la fe, por ser el estable y firme fundamento, o puerta de los demás sacramentos (...) Por tanto, puesto este fundamento, que una vez admitido ya no se pierde (...), la edificación del sacramento del matrimonio, como la de los demás sacramentos, se asienta y edifica firme y se adhiere a él como inseparablemente conglutinada y, por ello, es indisoluble este matrimonio edificado encima, como su fundamento. Pero, faltando esta base, aunque el edificio sea verdadero, sin embargo, es más débil”"46.

También valoraron los canonistas clásicos, desde la significación sacramental del matrimonio, la entidad específica del matrimonio consumado: "Una vez que hay cópula, (el matrimonio) significa una realidad indisoluble, la unidad existente entre Dios y la Iglesia por la asunción de la carne humana en las entrañas de la Virgen, como se dice en la Decretal Debitum, de bígamis ${ }^{47}$. (...) Por tanto, como el significado es inseparable así también lo es el mismo sacramento que lo significa, y esta razón no existe antes de la consumación"48.

\section{La presentación del personalismo en sustitución de la dimensión jurídica del matrimonio}

Ha sido considerado el personalismo -con su específica afirmación de la dignidad de la persona humana- una teoría representativa de la filosofía cristiana" ${ }^{\prime 49}$.

${ }^{46}$ El Hostiense, Lectura in IV Decretalium, rub. De divortiis, cap. VII, 8, Lyon1537, fol. 118. Más referencias sobre el valor del matrimonio rato pueden verse en T, Rincón, El matrimonio misterio, pp. 442-443, voces: Ratificación del vínculo, Indisolubilidad del no consumado; también en E. Tejero, El matrimonio misterio..., pp. 564-566, voces: Matrimonio no consumado; Ratificación del matrimonio, Significación de la unión de los cuerpos, «Una caro».

${ }^{47}$ X, I, XXI, 5.

${ }^{48}$ Nicolás de Tudeschis (El Panormitano), Commentaria super Decretalium, lib. III, rub. De conversione conjugatorum, cap. Ex publico, n. 13, Lugduni 1531, fol $167 \mathrm{v}^{\circ}$. Cfr. E. Tejero, El matrimonio misterio..., p. 43. Más referencias sobre este punto ibidem, p. 564, voz: Matrimonio consumado. También en T. Rincón, El matrimonio misterio..., voz: Consumación del matrimonio, p. 441.

${ }^{49}$ L. Pereyson, Esistenza e persona, Genova 1985, p. 174. Una cosideración más detenida de este punto puede verse en: S. Álvarez Turienzo, El Cristianismo y la formación del concepto de persona, en AA VV, Homenaje a Xavier Zubiri, Madrid 1970; K. E. Borresen, L'antropologie théologique d'Augustin et de Thomas d'Aquin. La typologie home-fame dans la tradition et dans l'eglise d'aujourd'hui, en "Recherches de Sciences Religieuses", 69, 3 (1981), pp. 393ss.; M.M. Campelo, Los valores de la intimidad: iniciación a una antropología agustiniana, en "Estudio Agustiniano" 20 (1985) 3, pp. 529-570; E. Forment, El personalismo de Santo Tomás, en 
Pero, como ha hecho notar A. Rodríguez Luño, si bien la cultura actual -también la que no responde inmediatamente a una inspiración religiosa- se caracteriza por una viva sensibilidad personalista, "esta sensibilidad es interpretada de maneras muy diversas, a veces incluso contrapuestas" $"$.

Surgido en Francia ${ }^{51}$, con E. Mounier, al rededor de los años 30, este mismo autor declaraba así su significado: "Llamamos personalista a toda doctrina, a toda civilización que afirma el primado de la persona humana sobre las necesidades materiales y sobre los mecanismos colectivos que sostienen su desarrollo" ${ }^{2}$. Sin embargo, en orden a una más precisa determinación de lo que significa el personalismo, debemos tener en cuenta que "no habría nada más falso que hablar del personalismo como de una escuela o de una doctrina. Es un fenómeno de reacción contra los errores opuestos y es inevitablemente un fenómeno complejo.

El personalismo ha puesto en juego una serie de conceptos anteriormente desconocidos en la reflexión filosófica, como amor, donación, diálogo, relaciones humanas. Y, como reflejo del éxito alcanzado por esta corriente, se suele destacar la frecuencia con que aparece en el actual debate cultural, su contribución a la debilitación ideológica de los grandes sistemas totalitarios y su incidencia en eventos culturales como la Declaración Universal de los Derechos del Hombre, en las categorías antropológicas de la Constitución italiana posterior a la segunda guerra mundial o en las formulaciones de la Constitución Pastoral Gaudium et spes. Sin embargo, no faltan opiniones que consideran que esta corriente doctrinal es demasiado lábil, flexible y genérica, de manera que ya habría conseguido prácticamente todo lo que sus recursos teóricos le permiten.

A partir del núcleo originario de sus planteamientos, que es la consideración de la persona como centro de la civilización, presta el personalismo una

\footnotetext{
"Sapientia" 45 (1990), pp. 277-294; J. García López, Doctrina de Santo Tomás sobre la verdad, Pamplona 1967; R. Guardini, Mundo y persona, Madrid 1954; A. Milano, Persona in Teologia. Alle origini del significato di persona nel cristianismo antico, Napoli 1984; R. R. Ruether, Imago Dei, Christian Tradition and Feninst Hermeneutics, en K.E. Borresen (ed.), Image of God and gender Models in Judeo-Christian Tradition, Oslo 1991, pp. 258-281; J. Sancho, Imagen de Dios y dignidad humana, AA. VV., VI Simpso Intern. Univ. de Navarra, Pamplona 1985, pp. 495-504.

${ }^{50}$ A. Rodríguez Luño, El primado de la persona en la moral fundamental, en A. Sarmiento, E. Molina, A. Quirós, J. Peñacova, J. Enériz (eds.), El primado de la persona en la moral contemporánea, Pamplona 1997, pp. 63-64.

${ }^{51}$ Aunque no se debe ignorar el personalismo norteamericano de principios de siglo, con autores como Bowe, Howiso, Flewelling y Brightmann. También en Italia autores como Stefanini, Pareyson, Carlini, Buttiglione. En lengua alemana R. Guardini, F. Ebner y H. U. von Balthasar. Y En España, J. Marías, A. López Quintas y otros.

${ }^{52}$ E. Mounier, Manifiesto al servicio del personalismo, Madrid 1972, p. 9.
} 


\section{The Person and the Challenges \\ 180

atención prioritaria el juego de mutuas implicaciones que mantienen la persona y la comunidad, como ideal de la sociedad. De ahí que una de sus tesis más características sea considerar el principio de comunión como constitutivo de la vida personal; alejándose así de los planteamientos que insisten en el principio de la individualidad máxima e incomunicabilidad de la persona. Se comprende, pues, que el personalismo insista en que la persona humana no se realiza si no es en comunión con los demás, en que "el yo y el tú son el uno para el otro, a la vez, causa y efecto" 53 , en que el yo se desarrolla en la conciencia de la comunión, en la experiencia de la amistad y del amor.

Siendo uno de los pilares básicos del personalismo su doctrina sobre la reciprocidad humana, como base de la reciprocidad de las conciencias, cuya comunicación obliga a diferenciar la participación, la asimilación y la comunión de las personas, ningún banco de pruebas les puede ser tan atractivo, para mostrar la riqueza de su doctrina, como sus análisis de la comunidad matrimonial y familiar, cuya densidad personal hecha un "nosotros", no tiene parangón entre los tipos de relaciones humanas. De ahí que hayan dedicado especial atención al estudio del matrimonio eminentes representantes del personalismo francés, como G. Madinier ${ }^{54}$, J. Lacroix ${ }^{55}$ o M. Nedoncelle ${ }^{56}$. Como exponente de esos planteamientos, aquí nos vamos a referir a la doctrina del primero de esos autores, recientemente expuesta por A. Sarmiento en un trabajo que nos he resultado particularmente útil ${ }^{57}$.

Para comprender adecuadamente la doctrina de Madinier sobre el matrimonio resulta clave tener en cuenta que "para él 'la conciencia' del 'yo' es, en el fondo, conciencia del 'nosotros'. La conciencia 'justa' del 'yo personal' es la conciencia moral, la conciencia del 'yo' responsable ante alguien que es superior y transcendente a él; y, por eso, la experiencia del yo personal es inseparable de los valores transcendentes: psicología y ética son inseparables" ${ }^{158}$.

Por consiguiente, el horizonte en que deben ser leídas las reflexiones de Madinier y, de los demás personalistas, es el ético existencial en que deben

${ }^{53}$ M. Nédoncell, La réciprocité des consciencies. Essai sûr la nature de la personne, Paris 1942 , p. 320.

${ }^{54}$ Conscience et amour: Essai sur le "nous", Paris 1962; Nature et mystère de la famille, Paris 1962.

${ }^{55}$ Personne et amour, Paris 1955; Force et faiblesses de la famille, Paris 1948.

${ }^{56}$ Nature et mystère de la famille, Aubier 1963.

${ }^{57}$ A. Sarmiento, El "nosotros" del matrimonio. Una lectura personalista del matrimonio como «comunidad de vida y amor», en "Scripta theologica", XXXI. (1999), pp. 71-102.

${ }^{58}$ Ibidem, pp. 79-80. 
moverse las personas integradas en la comunidad matrimonial o familiar, y en el cual cada uno se realiza contribuyendo a realizar la comunidad de personas.

Desde esa perspectiva, se habla de la tarea de "fundar un hogar" que deben realizar los esposos, del matrimonio como "una realidad a construir", como consecuencia de "fundar un nosotros" -unidad de dos-, en cuyo interior, cada uno de ellos deja de ser un "él" y, permaneciendo "yo" y "tú", se convierten en un "nosotros", siendo el "uno" para el "otro". Es decir, estamos ante la pretensión de mostrar la naturaleza y la calidad de ese modo de "hacer" de los casados para que su unión funde ese "nosotros" del hogar. Y, al desplegar los criterios orientadores de esa tarea, Madinier, en línea con la visión transcendente que caracteriza al personalismo francés, insiste en la necesidad de que los esposos sean fieles a las "leyes esenciales" del matrimonio institución, por lo cual, el "nosotros" del matrimonio tiene dos significados: a) el trascendente, anterior y por encima de los esposos, que son los elementos institucionales, irreformables y permanentes, por los que la unión de los esposos está llamada a ser según su propia naturaleza; b) el dependiente del existir de los esposos como respuesta fiel a esas "leyes esenciales" ${ }^{\prime 5}$. Estamos, pues, ante un planteamiento de admirable armonía, entre la tarea existencial a realizar por los esposos y las bases institucionales del matrimonio, cuyas "leyes esenciales" guían siempre las actuaciones personales en comunión. Y precisamente esa armonía contrasta con los graves desequilibrios en que han incurrido ciertos canonistas, al atribuir a la realización existencial del matrimonio una incidencia en el ser o no ser de la misma institución matrimonial, que está bien lejos del equilibrio personalista que venimos siguiendo.

La visión ético-moral del matrimonio y la familia que nos ofrece el personalismo francés es muy respetuosa también con el orden institucional del matrimonio, hasta el extremo de extraer, de esa constitución divina, las "leyes esenciales" que han de guiar a las personas en la realización ético-existencial de ese hogar, con las notas típicas que lo caracterizan. No cabe decir lo mismo de los planteamientos canónicos que consideran esencial la posibilidad capacidad para cumplir las "obligaciones esenciales" del matrimonio; porque, trasladando al ámbito jurídico la consideración de la realización ético-existencial a que se refiere el personalismo, dan origen necesariamente a un cambio esencial en la significación que el personalismo venía dando a la realización del matrimonio y la familia: ya no alude a la trayectoria ético-moral de la vida conyugal y familiar, sino a la constitución jurídica del matrimonio.

Este cambio sustancial en el significado ético-existencial que el personalismo francés venía dando a la realización del matrimonio, para ubicar ese concepto en

\footnotetext{
${ }^{59}$ Ibidem, pp. 83-84.
} 
el hacerse del matrimonio, en el sentido jurídico, a lo largo de la vida matrimonial, es particularmente claro en planteamientos como los de J. Bernhard, que afirma la insuficiencia del consentimiento para hacer el matrimonio, porque pretende destacar la importancia del sí péregrinant que precede, acompaña y sigue a la celebración del matrimonio. Entonces el matrimonio, jurídicamente hablando, no es un estado estático, sino un proceso, cuya realización y cumplimiento efectivo hace padecer al vínculo por exigir una actualización incesante de los factores constitutivos del matrimonio, a lo largo de la vida conyugal, y en referencia a la globalidad de su existencia. Según esta opinión, la fidelidad y la duración en el matrimonio tendrían fuerza de inventiva creadora jurídicamente hablando en la misma constitución del orden institucional del matrimonio. Así, se pretende que la vida matrimonial se constituya en fuente directa de las decisiones de nulidad que dan los jueces ${ }^{60}$.

Por su parte P. Huizing presentó el personalismo como clave interpretativa de un supuesto alejamiento del Código vigente respecto de las enseñanzas matrimoniales del Vaticano II. De acuerdo con esa pretensión, su exposición sobre la visión personalista del matrimonio se presenta en tres epígrafes: La concepción contractualista del CIC17, la concepción personalista del Vaticano II, el compromiso del "Schema de sacramentis" previo a la actual Codificación ${ }^{61}$. En el primer apartado, Huizing insiste en algo que ya hemos expuesto: el CIC17 hizo gravitar en exceso, sobre el concepto contrato, la contemplación del matrimonio En línea también con una certeza generalizada, dice Huizing que el Vaticano II, al insistir en la presentación del matrimonio como unión, don recíproco, alianza, consentimiento de dos personas, hombre y mujer, manifiesta una concepción personalista del matrimonio. Como consecuencia, entiende Huizing que el Derecho de la Iglesia sobre el matrimonio ha de ser también un Derecho personalista, que sería el de los derechos fundamentales del hombre y el de los derechos de los fieles. En ese ámbito, dice Huizing que existen verdaderas obligaciones y derechos, pero considera "que estas relaciones de justicia no son relaciones jurídicas. Sobre estas relaciones nosotros no podemos hacer contratos.

${ }^{60}$ Vid. J. Berbard, La duré du mariage et ses implications canoniques. En "Revue de Droit Canonique" 33 (1983), pp. 278-282. Aunque este planteamiento es conocido en los ambientes canónicos por haberlo propuesto reiteradamente el citado autor, en realidad, ya antes había sido propuesto por E. Schillebeeckx, Het chriten buwelijk en de menselijke realiteit van volkomen buwelijksonwrichting, en "Annalen van het Tbymgenootschap" 58 (1970) 188 ss Cf. T. G. Belmans, Le sens objectif de l'agir humain. Pour relire la moral conjugale de Saint Thomas, Città del Vaticano 1980, p. 341.

${ }^{61}$ P. Huizing, La concepcion du mariage dans le code, le Concile et le "Schema de sacramentis", en "Revue de Droit canonique" 27 (1977), pp. 135 ss. 
No hay un ius ad rem o un ius in re. Estas relaciones son inaccesibles a las leyes o mandatos o sanciones exteriores y autoritarias. No hay objetos jurídicos, cosas, prestaciones exteriores impersonales. Porque estas relaciones no pueden existir independientemente de la relación personal entre los sujetos de estas relaciones. Aquí la justicia se hace en plena libertad personal, o no se hace" ${ }^{\text {" }}$. Como consecuencia, priva a tales derechos que llama fundamentalesde su naturaleza jurídica, pues es precisamente en el ámbito del Derecho donde deben operar, como garantía de rango fundamental respecto de las disposiciones jurídicas de rango inferior, para reducirlos al puro ámbito moral: "Vosotros tenéis derecho a mi confianza, pero si yo no os la doy libremente, no me podéis forzar a ello y ni siquiera lo queréis vosotros, porque una confianza forzada es un contrasentido. Uno puede aspirar sólo a una confianza forzada hacia cualquiera, a una expresión puramente exterior, falta de confianza. Vosotros queréis y tenéis derecho a una confianza verdadera, sincera, libre y espontánea" ${ }^{3}$.

Por consiguiente el derecho personalista de que habla Huizing está privado de toda naturaleza jurídica para hacer referencia al puro ámbito interior de las decisiones personales, en que sólo la moral puede hacer sus típicas calificaciones, y desde esa base concluye que no cabe hablar de actos válidos o inválidos, porque esas categorías pertenecen a una visión estática del Derecho, que él considera superada: "Es evidente que no pueden aplicarse a las relaciones de justicia personalista las calificaciones jurídicas de 'validez' o 'invalidez"' ${ }^{64} \mathrm{y}$, consiguientemente, ignora la existencia de un vínculo conyugal. En algún momento, alude Huizing a la "unión personal de los esposos" a la "unión de sus personalidades" o de sus "subjetividades" ${ }^{65}$, pero cubre con un silencio total el vínculo matrimonial. Así se explica que

Huizing considere que es imposible verter en términos canónicos las enseñanzas conciliares y que los trabajos preparatorios de la Codificación canónica

${ }^{62}$ Ibidem, p. 139.

${ }^{63}$ Ibidem, p. 140.

${ }^{64}$ Ibidem.

65 "En la concepción personalista, el matrimonio es alianza conyugal, la unión misma entre el hombre y la mujer; es la unión misma de sus personalidades, de sus subjetividades, con todas las expresiones que de ahí se derivan, comprendida la unión corporal. En la concepción contractualista se ha comprendido ya que no se pueden separar unos derechos matrimoniales de otros; el derecho a la unión corporal no puede existir sin el derecho a la comunidad de vida, a la fidelidad etc. En la concepción personalista, se ha ido más lejos: el conjunto de los derechos matrimoniales no puede existir fuera de la unión personal de los esposos. En la concepción contractualista la unión personal -el amor conyugal- no puede ser un elemento constitutivo del matrimonio. En la concepción personalista, es la unión personal misma la que hace que los derechos entre el hombre y la mujer sean verdaderamente derechos matrimoniales". P. Huizing, La concepcion..., p. 141. 


\section{The Person and the Challenges \\ 184

hoy vigente fueron un puro compromiso intermedio entre el contractualismo del CIC17 y el personalismo del Vaticano II: "Todo el sistema del proyecto (del nuevo Código) está siempre centrado sobre la validez o la invalidez del contrato matrimonial, esto es, sobre la indisolubilidad y la disolubilidad de la relación jurídica del matrimonio. En efecto, la consecuencia de la concepción personalista del matrimonio más dura para los canonistas y también la más difícil de comprender por ellos es que no es posible aplicar al matrimonio personalista las nociones jurídicas de 'validez' o 'invalidez'. Yo me doy cuenta de que esto es el derrumbe de toda nuestra ingeniosa construcción jurídica" ${ }^{" 66}$.

\section{El criterio personalista en el Magisterio de Juan Pablo II y su intrínseca dimensión jurídica}

Como si pretendiera dar una respuesta directa al planteamiento que acabamos de ver, ha destacado Juan Pablo II que "es necesario tener bien claro el principio según el cual el valor jurídico no se yuxtapone como un cuerpo extraño a la realidad personal del matrimonio, sino que constituye una dimensión verdaderamente intrínseca a él (...). Poner a la persona en el centro de la civilización del amor no excluye el derecho, sino que más bien lo exige, llevando a su realidad como realidad interpersonal y a una visión de las instituciones jurídicas que ponga de relieve su vinculación constitutiva con las mismas personas, tan esencial en el matrimonio y la familia" 67 .

Por otra parte, hace notar el Papa que, lejos de toda contraposición entre el personalismo del Vaticano II y los planteamientos del CIC vigente, como afirmaba Huizing, debe destacarse que "en el Código de 1983 se funden armoniosamente formulaciones de origen conciliar como las referentes al objeto del consentimiento (cf. c. 1057, § 2) y la doble ordenación natural del matrimonio (cf. c. 1055, § 1), en las que se ponen directamente en primer plano las personas de los contrayentes (...). Sin embargo, hay síntomas que muestran la tendencia a contraponer, sin posibilidad de una síntesis armoniosa, los aspectos personalistas a los más propiamente jurídicos: así por un lado, la concepción del matrimonio como don recíproco de las personas parecería deber legitimar una indefinida tendencia doctrinal y jurídica a la ampliación de los requisitos de capacidad y madurez psicológica y de libertad y consciencia necesarias para contraerlo válidamente; por otro, precisamente ciertas aplicaciones de esta tendencia, evidenciando

\footnotetext{
${ }^{66}$ P. Huizing, La concepcion..., p. 142.

${ }^{67}$ Juan Pablo II, Alocución, 27. I. 1997, n. 3.
} 
los equívocos presentes en ella, son percibidas justamente como contrastantes con el principio de la indisolubilidad, reafirmado con la misma fuerza por el Magisterio" 68 .

Esa armonía entre los criterios personalistas y la dimensión jurídica del matrimonio ya había sido expuesta por destacados representantes del personalismo francés, como G. Madinier al señalar que es necesario un marco ético-jurídico, público, que regule tanto el constituirse como el desplegarse de la unión del matrimonio, que no puede ser un asunto privado, limitado en exclusiva a la intimidad de los que se casan. Están implicados unos bienes y valores de tal naturaleza, ya que la institución es necesaria siempre, antes que como imperativo jurídico, como exigencia del amor de los esposos, pues el lenguaje de la sexualidad es expresivo del amor y del bien de la sociedad, cuya existencia y calidad está comprometida en esta unión ${ }^{69}$. Junto a la ley de la institución, también son "esenciales" la ley de la unidad (monogamia), como exigencia de la dignidad común de los esposos y su amor total; la ley de la indisolubilidad y la ley de la fecundidad o de apertura a la prole y a su bien ${ }^{70}$. Pero, en esta forma de unión, la persona es lo que cuenta, precisamente en lo que tiene de más singular e insustituible: es la persona en cuanto tal la que se da y recibe esa unión que, de esa manera, es cauce de enriquecimiento y perfeccionamiento mutuos ${ }^{71}$.

${ }^{68}$ Ibidem, n. 2.

${ }^{69}$ G. Madinier, Nature et..., p. 21.

${ }^{70}$ Ibidem, pp. 20-21.

${ }^{71}$ Ibidem, pp. 49-50 y 95-96. Esta consideración personalista de la mutua integración existencial del hombre y la mujer se ha proyectado en una dilatada bibliografía que aquí sólo cabe indicar a modo de ejemplo: E. Badinter, L'un est l'autre. Des relations entre hommes et femmes, Paris 1986; G. Blaluiere, La grâce d'être femme, Paris 1987; B. Castilla Cortazar, La complementariedad varón-mujer. Nuevas hipótesis, Madrid 1993; Idem, Igualdad y diferencias entre varón y mujer, “Atlántida” 6 (1991), pp. 162 ss.; Idem, La persona y su "estructura” familiar. Dimensiones paterna y materna de la Doctrina social, en F. Fernádez (ed.), Estudios sobre la enc. "Centesimus annus”, Madrid 1992, pp. 199-226; Idem, Las coordenadas de la estructuración del “yo”. Compromiso y fidelidad en Gabriel Marcel, en "Cuadernos de Anuario Filosófico", Pamplona 1994; Idem, Persona y modalización sexual, en AA. VV., Metafísica de la familia, Pamplona 1995, pp. 69-105; J. M. Coll, Filosofía de la relación interpersonal, Barcelona 1990; J. Ferrer Arellano, Filosofía de la relación, en Filosofía de las relaciones jurídicas, Madrid 1963, pp. 183-300; J. Guiton, Ensayo sobre el amor humano, Buenos Aires 1968; J. M. Reinisch - L.A. Rosenblun - S.A. Sanders (dirs.) Masculinity/Feminity, Oxford 1987; E. Martín López, Comunicación hombre-mujer. Análisis tipológico desde las perspectivas de las actitudes vitales, Madrid 1991; J. Rof Carballo, El hombre como encuentro, Madrid 1973; A. Scola, Identidad y diferencia. La relación hombre-mujer, Madrid 1989; A. Valcárcel, Sexo y filosofía. Sobre mujer y poder, Barcelona 1991. 
Ya en su tesis doctoral ${ }^{72}$, destacaba Karol Wojtyla la naturaleza personal del encuentro del hombre con Dios, que hace a los creyentes ser más auténticamente ellos mismos y que, a través de la propia entrega, imprescindible para el conocimiento personal, es como conocemos a Dios. Como dos personas que se aman llegan a vivir una "dentro" de la otra sin perder sus propias y únicas identidades, Dios llega a vivir en nuestro interior y, en cierto sentido, nosotros llegamos a habitar "dentro de Dios", sin que se pierdan las diferencias radicales entre Creador y criatura. Más tarde, al profundizar en los fundamentos de la ética, entendió que la experiencia moral que tiene el ser humano sobre la diferencia que media entre la persona que soy y la persona que debo ser constituye el escenario en que se presentan las grandes cuestiones morales del bien y del mal, de la virtud y del deber ${ }^{73}$. A partir de esas bases, cuando, en su estudio, Amor y responsabilidad ${ }^{74}$ desarrolle Karol Wojtyła la moralidad sexual, lo hará mostrando que el amor es una expresión de la responsabilidad personal, de la responsabilidad hacia otro ser humano, y también hacia Dios. Así la norma personalista, variante de Wojtyla sobre el segundo imperativo categórico de Kant, será la puerta por donde se adentrará en la reflexión sobre la ética de la sexualidad humana: el imperativo moral de evitar "utilizar" a los demás constituye la base hacia la libertad, porque nos permite relacionarnos con los otros sin reducirlos a objetos al manipularlos. De ahí que la donación mutua en una communio personarum, sea el valor moral más típicamente ordenador de las relaciones entre los cónyuges ${ }^{75}$.

Madurado así, durante años, el criterio personalista de Karol Wojtyla, se comprende que, una vez constituido Papa, desplegara un Magisterio iluminador del significado personalista del cuerpo humano y su sentido esponsalicio, que, siendo básico para percibir el sentido del orden moral propio de la comunidad de vida matrimonial, es al mismo tiempo de obligada aceptación en las valoraciones específicamente propias de otros saberes, llamados a entender el orden divino del matrimonio, y concretamente en el cometido que corresponde a los estudiosos del Derecho matrimonial canónico.

En línea con el respeto que los representantes del personalismo francés mantienen hacia el misterio del matrimonio, la contemplación personalista que hace Juan Pablo II de la masculinidad y la feminidad, del cuerpo, como base de la comunión interpersonal y del significado esponsalicio del cuerpo, que revela el

${ }^{72}$ K. Wojtyła, La fe en San Juan de la Cruz, Madrid 1997. Cfr. G. Weigel, Biografía de Juan Pablo II. Testigo de esperanza, Barcelona 1999, p. 127.

\footnotetext{
${ }^{73}$ Ibidem, p. 181.

${ }^{74}$ Barcelona 1996.

${ }^{75}$ Cf. G. Weigel, Biografía..., pp. 201-202.
} 
don de Dios Creador y Redentor, se inspira en los trazos con que el Génesis nos presenta la creación del hombre y de la mujer. Estamos ante un personalismo basado en un conocimiento que Juan Pablo II califica como "teológico y antropológico"76; que, pretendiendo ofrecer el ethos humano del don de sí, lo hace siempre a partir de la contemplación del orden divino inherente a la diferenciación de sexos, tanto "en el principio", como en las etapas sucesivas de la Historia de la salvación. Es decir, estamos ante una presentación del criterio personalista que penetra en la entraña del plan divino de salvación con las implicaciones canónicas que se derivan de él.

Es el cuerpo humano y la diferencia de sexos -la masculinidad y la feminidadel eje de este personalismo. Sobre esa base, asienta el Papa el significado esponsalicio del cuerpo, que revela el misterio de la creación como don del Amor donador y creador de Dios, y la pura verdad de comunión existente entre las personas sexuadas. Está, pues, el cuerpo humano cargado de significación: expresa la persona, revela el alma viviente y, además, por la reciprocidad de la masculinidad y la feminidad, a través del don personal, es signo del Amor donador de Dios, que hace posible la plenitud del hombre mediante el don de sí $^{77}$.

Esa plenitud que el varón y la mujer están llamados a lograr mediante el don de sí confiere su significación específica al consentimiento matrimonial. En efecto, "podemos decir que la inocencia interior (esto es, la rectitud de intención) en el intercambio del don consiste en una recíproca aceptación del otro, tal que corresponda a la esencia misma del don; de este modo, la donación misma crea la comunión de las personas. Por eso, se trata de acoger al otro ser humano y de aceptarlo, precisamente porque en esta relación mutua de que habla Gen. 2, 2325 el varón y la mujer se convierten en don el uno para el otro, mediante toda la verdad y la evidencia de su propio cuerpo, en su masculinidad y feminidad"78.

El hecho de que el pecado original y la concupiscencia incidan negativamente sobre la inocencia interior del primer hombre y la primera mujer, de manera que "en la experiencia del corazón la feminidad y la masculinidad, en sus mutuas relaciones, parecen no ser ya la expresión del espíritu que tiende a la comunión personal" 79 , no debe llevarnos a negar el sentido de entrega del don de sí que entraña el consentimiento matrimonial, pues Cristo "revela la verdad originaria del matrimonio, la verdad del 'principio', y liberando al hombre de la dureza del corazón, lo hace capaz de realizarla plenamente. Esta revelación alcanza su

\footnotetext{
${ }^{76}$ Juan Pablo II, Alocución, 16. I. 1980, n. 5.

${ }^{77}$ Idem, Alocución, 16. I. 1980, nn. 1-3.

${ }^{78}$ Idem, Alocución, 6. II. 1980, nn. 2-3.

${ }^{79}$ Idem, Alocución, 23. VII. 1980, n. 1.
} 
plenitud definitiva en el don de amor que el Verbo de Dios hace a la humanidad asumiendo la naturaleza humana y en el sacrificio que Jesucristo hace de sí mismo en la cruz por su Esposa, la Iglesia. En este sacrificio se desvela enteramente el designio que Dios ha impreso en la humanidad del hombre y de la mujer desde su creación, el matrimonio de los bautizados se convierte así en el símbolo real de la nueva y eterna alianza, sancionada con la sangre de Cristo" $"$.

Y esa restauración del hombre y del orden divino del matrimonio, implicando una nueva capacitación del varón y de la mujer para realizar, en el orden moral, la mutua entrega que alimenta la comunión de personas, implica también la reordenación del matrimonio según el orden institucional del principio. Porque, ahora, "en virtud de la sacramentalidad de su matrimonio, los esposos quedan vinculados uno a otro de la manera más profundamente indisoluble. Su recíproca pertenencia es representación real, mediante el signo sacramental, de la misma relación de Cristo con la Iglesia. Los esposos son, por tanto, el recuerdo permanente para la Iglesia, de lo que aconteció en la cruz; son, el uno para el otro y para los hijos, testigos de la salvación, de la que el sacramento los hace partícipes"81.

A partir de esta dignidad sacramental del don de sí que hacen el varón y la mujer en el consentimiento matrimonial, se destaca la importancia de la libertad con que ha de prestarse: "Varón y mujer, en el contexto de su 'principio' beatificante, están libres con la misma libertad del don. Efectivamente, para poder permanecer en la relación del 'don sincero de sí ' y para convertirse en este don el uno para el otro, a través de toda su humanidad hecha feminidad y masculinidad, deben ser libres precisamente de este modo. Entendemos aquí la libertad sobre todo como dominio de sí mismos (autodominio). Bajo este aspecto, esa libertad es indispensable para que el hombre pueda 'darse a sí mismo' para que pueda convertirse en don, para que (refiriéndonos a las palabras del Concilio) pueda 'encontrar su propia plenitud' a través de 'un don sincero de sí'”

Lejos de ser indigno de la persona humana entregarse en el compromiso matrimonial, como algunos planteamientos contractualistas habían insinuado, esa entrega es manifestación de autodominio y libertad interior; porque, siendo "don desinteresado de sí mismos, ese don precisamente permite a ambos, varón y mujer, encontrarse recíprocamente, en cuanto que el Creador ha querido a cada uno de ellos 'por sí mismo' (cf. Gaudium et spes, 24). Así el hombre, en el primer encuentro beatificante, encuentra de nuevo a la mujer y ella le encuentra a él. De este modo, él la acoge interiormente; la acoge tal como el Creador la ha

\footnotetext{
${ }^{80}$ Idem, Familiaris consortio, n. 13.

${ }^{81}$ Ibidem.

${ }^{82}$ Idem, Alocución, 16. I. 1980, n. 2.
} 
querido 'por sí misma', como ha sido constituida en el misterio de imagen de Dios a través de su feminidad, y recíprocamente ella acoge del mismo modo, tal como el Creador le ha querido, 'por sí mismo' y le ha constituido mediante su masculinidad. En esto consiste la revelación y el descubrimiento del significado 'esponsalicio' del cuerpo" ${ }^{83}$.

Esa mutua acogida del varón y la mujer, por sí mismos, nace de un amor personal de elección, que, como dice Santo Tomás, "añade sobre el amor una elección precedente, por lo cual, no se halla en el apetito concupiscible, sino en la voluntad" $"$. La misma donación sexual de los esposos "se realiza de modo verdaderamente humano solamente cuando es parte integral del amor con que el hombre y la mujer se comprometen totalmente entre sí hasta la muerte (...). El único lugar que hace posible esa donación total es el matrimonio, es decir, el pacto de amor conyugal o elección consciente y libre con la que el hombre y la mujer aceptan la comunidad íntima de vida y amor querida por Dios mismo, que sólo bajo esta luz mantiene su significado" ${ }^{\$ 5}$.

A partir de esa voluntad de compromiso, que es el consentimiento matrimonial, puede decir Juan Pablo II que "en el acto con que se expresa la donación debemos aceptar el valor simbólico de los compromisos asumidos. Quien se entrega lo hace con el conocimiento de obligarse a vivir su don para el otro; si el otro concede un derecho es porque tiene voluntad de obligarse; y se entrega con la intención de obligarse a realizar las exigencias del don total hecho libremente por él" ${ }^{\prime 86}$. Lo que no quiere decir que esa dimensión obligacional del consentimiento matrimonial sea incompatible con la recíproca complementariedad de los esposos, pues el amor conyugal "es esencialmente un compromiso con la otra persona, que se asume mediante un acto de la voluntad bien determinado" ${ }^{87}$. Y, desarrollando más el sentido de ese amor comprometido, se nos dice: "En el matrimonio, un hombre y una mujer se comprometen mutuamente mediante un inquebrantable lazo de total y mutua entrega. Una unión total de amor. Amor que no es una emoción pasajera o un apasionamiento temporal, sino una decisión libre y responsable de unirse por completo, en los momentos buenos y en los momentos malos, al propio cónyuge. Es el don de uno mismo al otro. Es un amor digno de ser proclamado a los ojos de todo el mundo. Es incondicional" ${ }^{\prime 88}$.

\footnotetext{
${ }^{83}$ Ibidem, n. 3.

${ }^{84} 1-2$ q. 26 , a. 3.

${ }^{85} \mathrm{~K}$. Wojtyła, Amour e responsabilité, p. 99.

${ }^{86}$ Juan Pablo II, Alocución, 28. I. 1982, n. 6.

${ }^{87}$ Idem, Alocución 21. I. 1999, n. 4.

${ }^{88}$ Idem,, Alocución, 31. V. 1982, n. 2.
} 
Los mismos contenidos psicológicos del acto de mutua entrega de los esposos ponen de relieve la connaturalidad con que el varón y la mujer, por amor, se comprometen al consentir en el matrimonio: es un amor "que comporta una totalidad en la que entran todos los elementos integrantes de la persona -reclamo del cuerpo y del instinto, fuerza del sentimiento y de la afectividad, aspiración del espíritu y de la voluntad-; tiende a una unidad profundamente personal, que, más allá de la unidad en una sola carne, lleva a no ser sino un solo corazón y una sola alma" 89 . Y esto en todas las latitudes y en todos los tiempos, porque "en el misterio de la creación, el hombre y la mujer han sido 'dados' por el Creador, de modo particular, el uno al otro, y esto no sólo en la dimensión de la primera pareja humana y de la primera comunión de personas, sino en toda la perspectiva de la existencia del género humano y de la familia humana. El hecho fundamental de esta existencia del hombre en cada una de las etapas de su historia es que Dios 'los creó varón y mujer', efectivamente, siempre los crea de este modo y siempre son así" $"$.

Lo cual no quiere decir que carezca el matrimonio cristiano de naturaleza específicamente sacramental, pues entonces tiene una riqueza específica su unión, ya que "los esposos participan como esposos, los dos, siendo pareja, hasta el punto de que el efecto primario e inmediato del matrimonio (res et sacramentum) no es la gracia sobrenatural en sí, sino el vínculo conyugal cristiano; una comunión de dos típicamente cristiana, porque representa el misterio de la encarnación de Cristo y su misterio de alianza. Y el contenido de la participación en la vida de Cristo es también específico, pues el amor conyugal comporta una totalidad en que entran todos los elementos integrantes de la persona -llamada del cuerpo y del instinto, fuerza del sentimiento y afectividad, aspiración del espíritu y la voluntad-; tiende a una unidad profundamente personal, aquélla en que más allá de la unión en una sola carne, lleva a no ser sino un solo corazón y una sola alma; exige la indisolubilidad y la fidelidad en la donación recíproca definitiva, y se abre a la fecundidad" ${ }^{\prime \prime}$.

A la vista de las enseñanzas contenidas en los textos que acabamos de ver, podemos entender por qué Juan Pablo II no se conformaba con la visión del consentimiento matrimonial que lo hiciera equivaler a la cesión de un derecho subjetivo o varios acordados por vía contractual, pues está necesitada de "una perspectiva más profunda y a la vez más cristiana" ${ }^{\prime 92}$.

\footnotetext{
${ }^{89}$ Idem, Alocución, 22. XI. 1981, n. 13.

${ }^{90}$ Idem, Alocución, 13. II. 1980, n. 4.

${ }^{91}$ Idem, Alocución, 3. XI. 1979, n. 4.

${ }^{92}$ Idem, Alocución, 28. I. 1982, n. 6.
} 


\section{Bibliography}

Burke C., L'oggetto del consenso matrimonial. Un'analisi personalistica, Torino 1997.

Gil Hellín, Constitutionis pastoralis “Gaudium et spes” sinopsis historica. De dignitate matrimonii et familiae fovenda, pars II, caput I, Pamplona1982.

Hervada J., El Derecho del Pueblo de Dios. Hacia un sistema de Derecho canónico, III. Derecho matrimonial, Pamplona 1970.

Marzoa A., Miras J., Rodríguez Ocaña R. (dir.), Comentario exegético al Código de Derecho canónico, III, Pamplona 1995, pp. 1019-1637.

Sarmiento A., Escrivá Ivars J., Enchiridion familiae: textos del magisterio pontificio y conciliar sobre el matrimonio y la familia (Siglos I a XX), Madrid 1992. 